\title{
Can I be sued for that? Liability risk and the disclosure of clinically significant genetic research findings
}

\author{
Amy L. McGuire, ${ }^{1,4}$ Bartha Maria Knoppers, ${ }^{2}$ Ma'n H. Zawati, ${ }^{2}$ and Ellen Wright Clayton ${ }^{3}$ \\ ${ }^{1}$ Center for Medical Ethics and Health Policy, Baylor College of Medicine, Houston, Texas 77030, USA; ${ }^{2}$ Centre of Genomics and Policy, \\ McGill University, Montreal, Quebec H3A OG1, Canada; ${ }^{3}$ Center for Biomedical Ethics and Society, Vanderbilt University, Nashville, \\ Tennessee 37203, USA
}

\begin{abstract}
Genomic researchers increasingly are faced with difficult decisions about whether, under what circumstances, and how to return research results and significant incidental findings to study participants. Many have argued that there is an ethical-maybe even a legal-obligation to disclose significant findings under some circumstances. At the international level, over the last decade there has begun to emerge a clear legal obligation to return significant findings discovered during the course of research. However, there is no explicit legal duty to disclose in the United States. This creates legal uncertainty that may lead to unmanaged variation in practice and poor quality care. This article discusses liability risks associated with the disclosure of significant research findings for investigators in the United States.
\end{abstract}

The return of individual research results and incidental findings to participants in genome research has stimulated extensive policy discussion and intense scholarly debate over the past several years. In the context of genome-wide research, it has been identified as one of the most pressing ethical challenges warranting immediate policy attention (Caulfield et al. 2008). Several professional bodies, in the United States and abroad, have published ethics recommendations suggesting an obligation to offer at least some individual research results to participants (National Bioethics Advisory Council 1999; Council for International Organizations of Medical Sciences 2002; United Nations Educational, Scientific and Cultural Organization 2003; Knoppers et al. 2006; Fabsitz et al. 2010; Office of Biorepositories and Biospecimen Research 2010; Cassa et al. 2012; World Medical Association 2013). Despite this, research suggests that genome scientists are not routinely returning research results or incidental findings to study participants (Heaney et al. 2010; Fullerton et al. 2012; McGuire et al. 2013; Ramoni et al. 2013). A survey of genome-wide association study (GWAS) investigators suggests that the fear of legal liability serves as both a motivation and a barrier to the return of results (Ramoni et al. 2013). On the one hand, investigators are concerned about their potential liability for failure to return results. In fact, Hank Greely suggests that not offering to return results may be illegal, at least in extreme circumstances where the results "pose a very high risk of a serious disease" (Greely 2007). On the other hand, investigators worry that they could be sued for adverse outcomes resulting from premature disclosure, the disclosure of inaccurate findings, or medical mismanagement resulting from disclosure. Yet, no United States regulations directly address this issue, and there is no clear case law to rely on. This creates legal uncertainty that may lead to unmanaged variation in practice and poor quality care (Wennberg 2004).

This article focuses on the disclosure of research results and clinically significant incidental findings (hereinafter "significant findings") in the context of genetic research. We do not address the equally important and controversial issue of potential liability related to disclosure of incidental findings in the clinical context. We also focus specifically on genomic research but recognize that the

\footnotetext{
${ }^{4}$ Corresponding author

E-mail amcguire@bcm.edu

Article published online before print. Article and publication date are at http://www.genome.org/cgi/doi/10.1101/gr.170514.113.
}

liability issues are similar for other areas of research, such as neuroimaging research, where investigators are likely to discover clinically significant findings in the research context. We therefore look to case law in these other areas to help inform our analysis. We limit our discussion to findings that the researcher has knowledge of. Some have argued that there is a moral duty to hunt for significant findings, at least in the clinical context (Evans 2013). For example, the American College of Medical Genetics and Genomics (ACMG) recently published "Recommendations on Incidental Findings for Clinical Exome and Genome Sequencing" (Green et al. 2013) that suggests that clinical laboratories have a duty to seek out certain genetic variants that meet a high threshold of clinical utility. The recommendations are limited explicitly to clinical sequencing, and we do not think they should apply to research because of important differences between the nature of research and clinical care, which we describe elsewhere (Clayton and McGuire 2012) and summarize below. However, the authors of the "Recommendations" recognize that they may inform the development of research standards (Green et al. 2013). To the extent that they become widely adopted by the genome research community, they could create a new standard of care.

Finally, we limit our analysis to United States law. At the international level, over the last decade there has begun to emerge a clear legal obligation to return significant findings discovered during the course of research (Table 1). The European Convention on Human Rights and Biomedicine (Oviedo Convention), as well as several national laws, indicate the emergence of a legal obligation to disclose and make arrangements for the communication of research results, including its meaning for both individuals and their families. Individuals who engage in research internationally should be aware of these laws and are responsible for complying with them.

\section{No explicit legal duty to disclose in the United States}

United States federal regulations for the protection of human research subjects (the "Common Rule"; Code of Federal Regulations)

(c) 2014 McGuire et al. This article is distributed exclusively by Cold Spring Harbor Laboratory Press for the first six months after the full-issue publication date (see http://genome.cshlp.org/site/misc/terms.xhtml). After six months, it is available under a Creative Commons License (Attribution-NonCommercial 4.0 International), as described at http://creativecommons.org/licenses/by-nc/ $4.0 \%$. 
Table 1. International laws on return of research results and significant incidental findings

\section{Council of Europe, Convention for the Protection of Human Rights and Dignity of the Human Being with Regard to the Application of Biology and \\ Medicine: Convention on Human Rights \\ and Biomedicine, ETS no. 164 Oviedo, \\ 4.IV.1997 (ratified by 29 countries to date) \\ Council of Europe, Additional Protocol to the Convention on Human Rights and Biomedicine, concerning Biomedical Research, CETS no. 195 Strasbourg, 25.1.2005}

Estonia, Human Genes Research Act, 2000

Spain, Law 14/2007 of 3 July on Biomedical Research, 2007

Taiwan, Human Biobank Management Act, 2010
1997

"Everyone is entitled to know any information collected about his or her health" (article 10)

2005

Required that researchers make "arrangements for access to information relevant to the participant arising from the research and to its overall results" (article 13.2[v]); moreover, "if research gives rise to information of relevance to the current or future health or quality of life of research participants, this information must be offered to them..." (emphasis added) (article 27)

2000

Gave donors "the right to access personally their data stored in GeneBank" (article 11.2)

2007

Mandates not only "the right to be informed of his or her genetic data" but also "the right not to know"; irrespective of the choice not to know however, such data would be communicated "to avoid serious damage to his health or that of his biological family members..." (article 5)

Requires "participants to be made aware of any possible impacts of the genetic information derived from the biological specimens on the participant, and his/her relatives or ethnic group" (article 7.8) do not specifically require the return of research results or clinically significant incidental findings. The Common Rule does require that investigators disclose to research participants the reasonably foreseeable risks and benefits of participating in the research and, when appropriate, findings developed during the course of the research that may relate to the subject's willingness to continue participation (Code of Federal Regulations). It could be argued that, at a minimum, this requirement obligates investigators to disclose the fact that significant findings might be discovered during the course of the research and whether or not those will be offered to subjects and/or their physicians. If specific findings might influence the subject's willingness to continue participation in the research, then there may be a duty to offer those results (Wolf et al. 2008). Ultimately, the statutory authority to ensure regulatory compliance and decide if a specific finding might influence a subject's willingness to continue participation and thus must be offered rests with the investigator's institutional review board (IRB). Yet, a recent study of IRB professionals reports that many IRB members are not comfortable with their expertise in genomic research, and few have actual experience addressing the issue of return of genetic research results (Dressler et al. 2012). Further, the Office of Human Research Protections (OHRP) has never directly addressed this issue, leaving IRBs with little guidance to make their determinations.

In addition to disclosing the risks and benefits of research, the Common Rule also requires researchers to minimize risks and ensure that these are reasonable in relation to the anticipated benefits. This suggests that investigators at least ought to have a plan for how to deal with significant findings to ensure that the risks of disclosure or nondisclosure are minimized (Wolf et al. 2008). It does not, however, create an obligation to disclose.

United States case law does not help clarify the legal obligations of researchers. No court has addressed directly the issue of a researcher's legal duty to disclose significant findings discovered during the course of research (Clayton et al. 2013). Nor have the courts addressed whether clinical geneticists have a legal duty to disclose incidental findings discovered during the course of routine genetic testing. Although not directly on point, there are eight legal cases involving claims of medical malpractice related to incidental findings from clinical radiologic imaging that may provide some guidance (Clayton et al. 2013). In three cases, the physician was found not to have breached the duty of care. Of the other five cases, only one (Lo v. Burke 1995) resulted in a finding of physician liability. The other four cases were likely settled.

\section{Negligence as a cause of action for nondisclosure}

Although there are several legal theories under which a researcher could be sued for failure to disclose significant findings (Tovino 2008; Bush and Rothenberg 2012), the most probable cause of action is ordinary negligence. Negligence is defined legally as "conduct which falls below the standard established by law for the protection of others against unreasonable risk of harm" (Restatement [second] of torts 1965). In order to prove negligence, the plaintiff must show that the defendant owed a duty to the plaintiff that was breached and caused compensable damages (Restatement [second] of torts 1965; Goldberg and Zipursky 2001). In order to determine whether a duty was breached, the courts look to what the standard of care is. The standard of care is defined typically by prevailing professional practice; that is, what would a reasonable researcher do under similar circumstances. This is established typically through expert testimony, which often relies on professional practice, published literature, and professional guidance documents (Clayton and McGuire 2012).

Also relevant is the nature of the relationship between the researcher and the participant. Legal obligations are generally role specific. Legal duties in research are therefore different from legal duties in clinical practice, and the legal duties of researchers vary depending on the nature of the relationship between the investigator and the participant. The physician-patient relationship is a fiduciary relationship, or a relationship held in trust (Zeigler $v$. Illinois Trust \& Savings Bank 1910; Bowman v. McPheeters 1947; Adams v. Ison 1952; Stafford v. Shultz 1954; American Jurisprudence 1972; Fure v. Sherman Hospital 1978). This creates special obligations for physicians to use their competence and skill to act primarily for the benefit of their patient (McCullough 2013). Researchers, on the other hand, have not traditionally been treated as fiduciaries (Moore v. Regents of the University of California 1990; Greenberg v. Miami Children's Hospital Research Institute 2003; Tovino 2008) because, as researchers, their primary obligation is to produce generalizable

\section{Genome Research}


knowledge, even if it requires actions that are not primarily for the benefit of the individual research subject. In some cases, health professionals have dual roles as physicians who are also conducting research on their patients. Although the law clearly distinguishes the individual's role-specific obligations, in reality it is sometimes difficult to separate the two.

Physicians who enroll their patients into research have an inherent conflict of interest. Their primary obligation as a researcher to ensure scientific integrity and create generalizable knowledge may, at times, conflict with their primary obligation as a physician to protect and promote their patient's health interests. This conflict is managed typically through the informed consent process in which the patient/participant is being asked to suspend the clinical relationship for a research relationship, as long as it does not significantly interfere with the patient's health interests. For example, consider a physician/researcher who is conducting a placebo-controlled trial for the off-label use of a drug that she believes will benefit patients with mild cognitive impairment, and her patient with mild cognitive impairment is randomized to receive the placebo. The physician/researcher is discouraged (typically by being blinded herself to the randomization process) from removing the patient/participant from the trial in order to prescribe the study drug because this would undermine the research process and make it impossible to systematically assess the risks and benefits of new drugs or new indications for existing pharmaceuticals. Keeping the participant in the study does not violate the physician's fiduciary responsibility to her patient because, although the physician believes the study drug will be more efficacious, there is not yet sufficient evidence to support this belief, creating clinical equipoise (Freedman 1987), which justifies the appropriateness of a scientific study in the first place. On the flip side, if the patient/participant is randomized to the study drug and experiences a significant adverse event, then the physician/ researcher has an obligation, as a physician and a researcher, to report the event and discontinue study participation.

In the context of genetic research, the type of research being done, the ways in which the research data are collected and stored, and the nature of the relationship between researcher and participant can all weigh heavily in determining liability. For example, it is unlikely that investigators will have an opportunity to discover clinically significant findings related to an individual when conducting population-based research that explores genomic variation in the aggregate. The risk of liability is therefore more limited in that context than when the research questions focus on interrogation of an individual's genome. Likewise, investigators who conduct research using anonymized data that cannot be traced back to an individual would not feasibly be able to return significant findings discovered during the course of the research and therefore should not be liable for failure to do so. Those participants who agree to the anonymized use of their data also likely have a heightened expectation of privacy that ought to be respected. With regard to the nature of the relationship, researchers who also have a physician/patient relationship with study participants may be more likely to have the professional competence and expertise to judge materiality of genomic information for medical decision-making, by considering it in the larger context and taking into consideration other test results, signs and symptoms discovered on physical examination, comorbidities, family history, and environmental exposures. For this reason, the courts may be more likely to find that physician/researchers who enroll their patients into the research have a higher duty to disclose relevant and significant findings.
It would be much more difficult to prove that a researcher who does not have a physician-patient relationship with the participant has a duty to disclose significant findings discovered during the course of the research. However, there may be a common law duty to rescue by disclosing a much higher threshold of immediately actionable findings. Except in limited circumstances, an individual generally has no duty to assist or obtain help for persons in distress or to warn of imminent danger (Keeton 1984). Yet, there are several exceptions to this rule when a legal duty to aid may be imposed, including "where one stands in a certain relationship to another" (State v. Miranda 1998). Whether and under what circumstances such a special relationship exists in research is unsettled. Several commentators (Miller et al. 2008; Richardson 2008; Wolf et al. 2008) and one court (Grimes v. Kennedy Krieger Institute Inc. 2001) have suggested a "special relationship" evolves from certain interactions between a researcher and subject that may give rise to heightened obligations. The one court case that has suggested that a special relationship may exist in research implies that it arises from the "very nature of nontherapeutic scientific research on human subjects" (Grimes v. Kennedy Krieger Institute Inc. 2001). This case has been heavily criticized, but one might nonetheless conclude that, to the extent a special relationship is recognized, it will be limited to investigators enrolling subjects into research and according to the terms of their consent forms.

Although it has never been directly addressed by the courts, it is difficult to imagine that a special relationship giving rise to a duty to rescue would be found based solely on the fact that the investigator is conducting research using a biological specimen from the subject, if they have not ever personally interacted with one another and the investigator has no way of knowing who the individual who provided the specimen is. The legal obligations of investigators who are conducting research using stored specimens and data should therefore be limited to those that are contractually created by the storage facility through appropriate use agreements, such as material transfer agreements, data use agreements, and memoranda of understanding.

Scholars have suggested other theories of liability, such as the theory of partial entrustment, in which even downstream researchers owe a duty of ancillary care to subjects because those subjects entrust relevant aspects of their health to researchers by waiving their rights to privacy with regard to their health information during the informed consent process (Richardson and Cho 2012). However, this theory has been criticized because research does not aim to promote individual health, and creating obligations of ancillary care would compromise the central mission of researchers to produce generalizable knowledge (Garrett 2013). There is also no case law to support the application of theories like partial entrustment to return of results in research (Tovino 2008).

\section{Liability for negligent disclosure}

Researchers also worry about potential liability associated with disclosure. Researchers who disclose significant findings (regardless of whether they have a duty to disclose) must do so competently and in a way that is consistent with standard practice. This requires that they comply with standards that seek to maximize the analytic and clinical validity of findings. For example, research laboratories often have less stringent standards for quality and accuracy than clinical diagnostic laboratories. Methods for documenting the chain of custody of samples are more rigorous in clinical laboratories because the consequences of a sample swap are 
more severe. It is required therefore, at least in the United States, that research results are validated in a clinically certified laboratory prior to return "for the diagnosis, prevention or treatment of any disease or impairment of, or the assessment of the health of individuals" (Meyers 2011). If a researcher returns erroneous results that have not been validated without making clear that the results need to be repeated before any clinical interventions are undertaken, and if that error results in compensable harm to a subject, then the researcher may be liable for negligence. Similarly, researchers who deviate from standard practice regarding variant calling and interpretation may be exposed to liability. Of course, as is true with any new technology, the standards are evolving rapidly, and there are many limitations in the ability to interpret accurately genomic data. Investigators should not be held legally accountable for errors in interpretation that can reasonably be expected given the novelty of the science, as long as subjects are informed of the limitations and associated risks. Again, the burden of proof will rest with the subject to prove that the researcher's actions fell below the standard of care and that those actions resulted in compensable harm to the subject. However, absent clearly defined and agreed upon standards, and given that there is still fervent debate about how to interpret variants and what, if any, results ought to be returned and how, it will be extremely difficult to prove what the standard of care is or that it has clearly been breached by a researcher acting in good faith.

\section{Conclusion}

In conclusion, there is very little legal precedent to determine the parameters of researchers' risk of liability at this point in time. Nonetheless, we can expect to see more litigation in this area, due in part to increasing public awareness and in part to numerous proposals, some of which are quite far reaching, to impose such responsibility on actors in the research enterprise (Wolf et al. 2012). The legal obligations of researchers will depend very much on the type of research being done, the ways in which the research data are collected and stored, and the researcher's relationship with the study participant, as well as emerging consensus on appropriate professional behavior. Guidelines, recommendations, and policy statements that are published by professional societies or groups of experts usually include a disclaimer that they are not intended to represent the standard of care. However, in the case of a lawsuit, both parties will rely on those documents to establish professional practice and define the obligations of researchers. The research community needs to be aware of the potential legal impact of these professional statements and should consider all of the ramifications when writing them and before embracing them, formally and in practice.

Leaving this issue to litigation will likely result in inconsistency across jurisdictions and court rulings that may not take into account the full complexity of the issue. Federal regulation could limit litigation by indemnifying investigators for failure to return results, while allowing them to do so when, in their professional judgment and with approval from an IRB, it is deemed ethically appropriate. Yet, there is no indication that this is on the horizon. For example, the United States Department of Health and Human Services is in the process of proposing substantial changes to the federal regulation of human subjects research (ANPRM 2011), but none of the proposed changes directly address this important issue. Absent regulatory protection, the fear of liability has a tendency to drive behavior. In the end, however, researchers should concern themselves more with the responsible stewardship of genomic data then with potential liability for their actions. Acting in good faith and using one's professional expertise to make good judgments are always the best defense.

\section{Acknowledgments}

This research was funded by NHGRI and NICHD 1R21HG00612-01. We thank Lainie Friedman Ross, MD, PhD for thoughtful comments on drafts of this manuscript, and Karen Frumovitz, JD and Lindsay Feuerman for their extremely helpful research assistance.

\section{References}

Adams v. Ison, 249 S.W. 2d 791 (Ky. 1952).

American Jurisprudence, 2nd ed. 1972. Physicians and surgeons, Vol. 61, sec. 100.

ANPRM (Advanced Notice of Proposed Rulemaking). 2011. Federal Register, Vol. 76, No. 143.

Bowman v. McPheeters, 77 Cal. App. 2d 795, 176 P. 2d 745 (1947).

Bush LW, Rothenberg KH. 2012. Dialogues, dilemmas, and disclosures: genomic research and incidental findings. Genet Med 14: 293-295.

Cassa CA, Savage SK, Taylor PL, Green RC, McGuire AL, Mandl KD. 2012. Disclosing pathogenic genetic variants to research participants: quantifying an emerging ethical responsibility. Genome Res 22: $421-$ 428, Table 1 .

Caulfield T, McGuire AL, Cho M, Buchanan JA, Burgess MM, Danilczyk U, Diaz CM, Fryer-Edwards K, Green SK, Hodosh MA, et al. 2008. Research ethics recommendations for whole-genome research: consensus statement. PLoS Biol 6: e73.

Clayton EW, McGuire AL. 2012. The legal risks of returning results of genomics research. Genet Med 14: 473-477.

Clayton EW, Haga S, Kuszler P, Bane E, Shutske K, Burke W. 2013. Managing incidental genomic findings: legal obligations of clinicians. Genet Med 15: 624-629.

Code of Federal Regulations, title 45, sec. 46.

Council for International Organizations of Medical Sciences (CIOMS). 2002. International ethical guidelines for biomedical research involving human subjects. http://www.cioms.ch/publications/ layout_guide2002.pdf.

Dressler LG, Smolek S, Ponsaran R, Markey JM, Starks H, Gerson N, Lewis S, Press N, Juengst E, Wiesner GL. 2012. IRB perspectives on the return of individual results from genomic research. Genet Med 14: 215-222.

Evans BJ. 2013. Minimizing liability risks under the ACMG recommendations for reporting incidental findings in clinical exome and genome sequencing. Genet Med 15: 915-920.

Fabsitz RR, McGuire AL, Sharp RR, Puggal M, Beskow LM, Biesecker LG, Bookman E, Burke W, Burchard EG, Church G, et al. 2010. Ethical and practical guidelines for reporting genetic research results to study participants. Circ Cardiovasc Genet 3: 574-580.

Freedman B. 1987. Equipoise and the ethics of clinical research. NEngl JMed 317: 141-145.

Fullerton SM, Wolf WA, Brothers KB, Clayton EW, Crawford DC, Denny JC, Greenland P, Koenig BA, Leppig KA, Lindor NM, et al. 2012. Return of individual research results from genome-wide association studies: experience of the Electronic Medical Records and Genomics (eMERGE) Network. Genet Med 14: 424-431.

Fure v. Sherman Hospital, 64 Ill. App. 3d 259 (1978).

Garrett JR. 2013. Reframing the ethical debate regarding incidental findings in genetic research. $A J O B$ 13: 44-46.

Goldberg JCP, Zipursky BC. 2001. The restatement (third) and the place of duty in negligence law. Vanderbilt Law Rev 54: 657.

Greely HT. 2007. The uneasy ethical and legal underpinnings of large-scale genomic biobanks. Annu Rev Genomics Hum Genet 8: 343-364.

Green RC, Berg JS, Grody WW, Kalia SS, Korf BR, Martin CL, McGuire AL, Nussbaum RL, O'Daniel JM, Ormond KE, et al. 2013. ACMG recommendations for reporting of incidental findings in clinical exome and genome sequencing. Genet Med 15: 565-574.

Greenberg v. Miami Children's Hospital Research Institute, 264 F. Supp. 2d 1064 (S.D. Fla. 2003).

Grimes v. Kennedy Krieger Institute Inc., 782 A. 2d 807 (Md. 2001).

Heaney C, Tindall G, Lucas J, Haga SB. 2010. Researcher practices on returning genetic research results. Genet Test Mol Biomarkers 14: 821827.

Keeton WP, ed. 1984. Prosser and Keeton on torts, 5th ed., sec. 56, p. 375. Thomson-Reuters, Eagan, MN. 
Knoppers BM, Joly Y, Simard J, Durocher F. 2006. The emergence of an ethical duty to disclose genetic research results: international perspectives. Eur J Hum Genet 14: 1170-1178.

Lo v. Burke, 249 Va. 311 (1995).

McCullough LB. 2013. Professional responsibility to and for patients and the ethics of health policy. Am J Bioeth 13: 16-18.

McGuire AL, Robinson JO, Ramoni RB, Morley DS, Jofe S, Plon SE. 2013. Returning genetic research results: study type matters. Per Med 10: 27-34.

Meyers P. 2011. CLIA and research results. In The Department of Health and Human Services Meeting of the Secretary's Advisory Committee on Human Research Protections (SACHRP).

Miller FG, Mello MM, Joffe S. 2008. Incidental findings in human subjects research: what do investigators owe research participants? J Law Med Ethics 36: 271-279.

Moore v. Regents of the University of California, 51 Cal. 3d 120, 793 P. 2d 479 (1990).

National Bioethics Advisory Council (NBAC). 1999. Research involving human biological materials: ethical issues and policy guidance. http:// bioethics.georgetown.edu/nbac/hbm.pdf.

Office of Biorepositories and Biospecimen Research, National Cancer Institute, National Institutes of Health. 2010. Workshop on release of research results to participants in biospecimen studies. http:// biospecimens.cancer.gov/global/pdfs/NCI_Return_Research_Results_ Summary_Final-508.

Ramoni RB, McGuire AL, Robinson JO, Morley DS, Plon SE, Joffe S. 2013. Experiences and attitudes of genome investigators regarding return of individual genetic test results. Genet Med 15: 882-887.
Restatement (second) of torts. 1965. Sec. 282.

Richardson HS. 2008. Incidental findings and ancillary-care obligations. J Law Med Ethics 36: 256-270.

Richardson HS, Cho MK. 2012. Secondary researchers' duties to return incidental findings and individual research results: a partial-entrustment account. Genet Med 14: 467-472.

Stafford v. Shultz, 42 Cal. 2d 767, 270 P. 2d 1 (1954).

State v. Miranda, 715 A. 2d 680 (Conn. 1998).

Tovino SA. 2008. Incidental findings: a common law approach. Account Res 15: $242-261$.

United Nations Educational, Scientific and Cultural Organization (UNESCO). 2003. International declaration on human genetic data. http://www.unesco.org/new/en/social-and-human-sciences/themes/ bioethics/human-genetic/data/.

Wennberg JE. 2004. Practice variations and health care reform: connecting the dots. Health Aff (Millwood) 2004: VAR140-VAR144.

Wolf SM, Paradise J, Caga-anan C. 2008. The law of incidental findings in human subjects research: establishing researchers' duties. J Law Med Ethics 36: 361-383.

Wolf SM, Crock BN, Van Ness B, Lawrenz F, Kahn JP, Beskow LM, Cho MK, Christman MF, Green RC, Hall R, et al. 2012. Managing incidental findings and research results in genomic research involving biobanks \& archived datasets. Genet Med 14: 361-384.

World Medical Association. 2013. World Medical Association Declaration of Helsinki: ethical principles for medical research involving human subjects. JAMA 310: 2191-2194.

Zeigler v. Illinois Trust \& Savings Bank, 245 Ill. 180 (1910). 


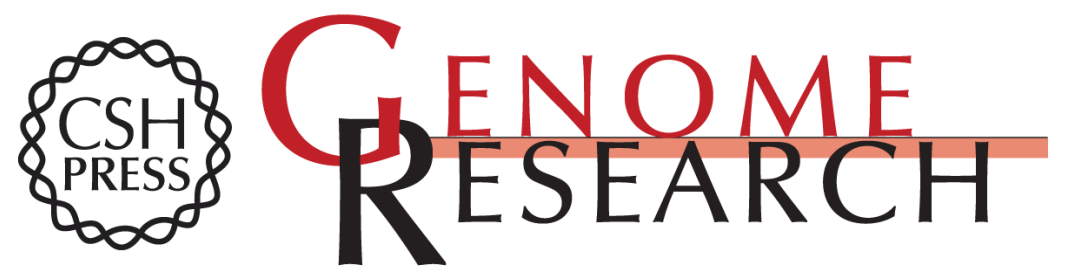

\section{Can I be sued for that? Liability risk and the disclosure of clinically significant genetic research findings}

Amy L. McGuire, Bartha Maria Knoppers, Ma'n H. Zawati, et al.

Genome Res. 2014 24: 719-723 originally published online March 27, 2014

Access the most recent version at doi:10.1101/gr.170514.113

References This article cites 27 articles, 2 of which can be accessed free at:

http://genome.cshlp.org/content/24/5/719.full.html\#ref-list-1

Creative This article is distributed exclusively by Cold Spring Harbor Laboratory Press for the Commons License first six months after the full-issue publication date (see

http://genome.cshlp.org/site/misc/terms.xhtml). After six months, it is available under a Creative Commons License (Attribution-NonCommercial 4.0 International), as described at http://creativecommons.org/licenses/by-nc/4.0/.

Email Alerting Receive free email alerts when new articles cite this article - sign up in the box at the Service top right corner of the article or click here.

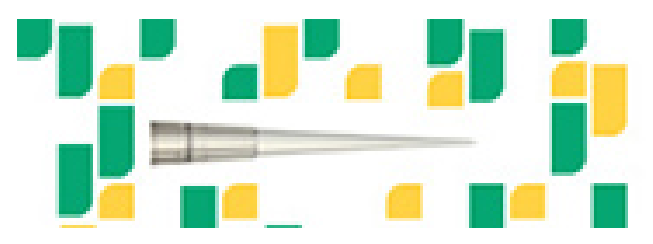

Focused on your science.

To subscribe to Genome Research go to:

https://genome.cshlp.org/subscriptions 